\title{
A COMPARATIVE ANALYSIS OF MEN AND WOMEN'S HOURLY EARNINGS IN POLAND WITH PARTICULAR EMPHASIS ON THE EDUCATION SECTOR
}

\author{
Joanna Landmesser, Ph.D., Associate Professor \\ Warsaw University of Life Sciences - SGGW, Institute of Economics and Finance \\ Nowoursynowska St. 166, 02-787 Warsaw, Poland \\ e-mail: joanna_landmesser@sggw.edu.pl \\ ORCID: 0000-0001-7286-8536 \\ Marian Rusek, Ph.D., Associate Professor \\ Warsaw University of Life Sciences - SGGW, Institute of Information Technology \\ Nowoursynowska St. 159, 02-787 Warsaw, Poland \\ e-mail: marian_rusek@sggw.edu.pl \\ ORCID: 0000-0002-9978-7530 \\ Olga Zajkowska, Ph.D. \\ University of Warsaw, Faculty of Economic Sciences \\ Dtuga St. 44/50, 00-241 Warsaw, Poland \\ e-mail:o.zajkowska@uw.edu.pl \\ ORCID: 0000-0001-6520-1303
}

Received 14 April 2020, Accepted 14 March 2021

\begin{abstract}
Research background: There is the lack of a sector based analysis of wages for different genders. We present such an analysis regarding the education sector in Poland.

Purpose: The study aims to compare hourly earnings for men and women in Poland, with particular emphasis on the education sector. We go beyond the simple Oaxaca-Blinder decomposition and compare earnings distributions.

Research methodology: First, we examine the hourly earnings inequalities using the Oaxaca-Blinder decomposition procedure. Second, we extend this procedure to different quantile points along the whole earnings distribution by the use of the residual imputation approach. The results are obtained for the whole sample (people of all professions), for a group of teaching professionals, and for university and higher education teachers.

Results: The magnitude of the gender hourly wage gap varies substantially depending on how the sample of interest is defined. It also heavily depends on the quantile of the analyzed distribution. Although the average
\end{abstract}


gap in the educational sector is negative, the differences turn positive and increase with higher quantiles of distribution in favor of men. The disparity was most pronounced for university top professionals.

Novelty: Our results provide novel insights into the sectoral dimension of the income gap. We analyze inequalities over whole distribution in the educational sector and compare them with wage inequalities in enterprises employing more than 9 people.

Keywords: wage gap, differences in distributions, decomposition methods, education sector

JEL classification: D31, J31

\section{Introduction}

The aim of this work is to compare hourly earnings for men and women in Poland, with particular emphasis on the education sector as gender differences in earnings are a well-known phenomenon of labor markets. The findings of numerous empirical studies show that males often earn higher wages than females. It may be the result of differences in personal (education, work experience, professional career, etc.) and job characteristics (different occupation, sector, type and size of the firm, etc.). Women's earnings on the average are lower and usually result from career breaks or part-time work due to childbearing. There are significant gendered pay inequalities in Poland - the raw wage gap is around 10\% and the adjusted pay gap estimates oscillate between 14 and 24\% depending on the calculation method (Goraus et al., 2017).

A variety of techniques for income inequalities analysis are becoming popular. For example, based on the Oaxaca-Blinder comparison of average income values (Oaxaca, 1973; Blinder, 1973) the structure of the gender wage gap in Poland was analyzed by Słoczyński (2012), Zajkowska (2013), Śliwicki and Ryczkowski (2014) or Cukrowska-Torzewska and Lovasz (2016). The obtained results confirmed that the gender wage gap can be poorly explained by gender differences in the observable characteristics of people. Even accounting for age, education, and work experience etc., the gap remains substantial. The unexplained component describing discrimination on the labor market quantitatively dominates. Nonetheless, Majchrowska, Strawiński, Konopczak and Skierska (2014) explored wage inequalities among various professions and showed that when we separate the effect of segregation of women into less-paid occupations the discrimination effect is much smaller.

According to Bergman, the author of the occupational segregation theory (Bergman, 1971), horizontal segregation occurs when women are crowded in less demanded professions which results in their salaries being lower. Therefore, numerous foreign studies have analyzed 
the impact of occupation as well as the proportion women in an occupation (feminization) on the gender wag gap (e.g., Addison, Ozturk, Wang, 2018). Particularly, interesting may be analyzes regarding the education sector. For example, in the case of vocational education in Poland Majchrowska et al. (2014) found that the gender wage gap occurs in favor of women. The opposite is true at universities. Male full professors at U.S. institutions earn $15 \%$ more than female full professors (Chen, Crown, 2017). Male academic teachers in Poland earn 15\% more compared with female colleagues (Majchrowska et al., 2014).

In our study, we want to go beyond the simple Oaxaca-Blinder decomposition and we intend to compare earnings distributions taking into account gender differences. To decompose the differences between the two distributions one can use the so-called counterfactual distribution, which can be constructed in various ways (see for example, DiNardo et al. (1996), Donald, Green and Paarsch (2000), Machado and Mata (2005), Fortin, Lemieux and Firpo (2010)). Examples of the applications of these techniques for the analysis of income inequalities in Poland are Matysiak, Baranowska and Słoczyński (2010), Słoczyński (2012), Landmesser, Karpio and Lukasiewicz (2015), Landmesser (2016). We will examine the differences along the whole earnings distributions by the use of the residual imputation approach (JMP-approach) (Juhn, Murphy, Pierce, 1993).

The results of our analysis provide novel insights into the sectoral dimension of the income gap. We analyze the earnings inequalities in the educational sector and compare them with inequalities in enterprises employing more than 9 people of different professions.

The paper is organized as follows: Section 2 describes the techniques used for the decomposition of inequalities, Section 3 presents the data, Section 4 gives the results of the decomposition analyses, and Section 5 offers some concluding remarks.

\section{Analysis method}

Let the dependent variable $Y_{g}$ represents the log hourly earnings in the group of men, $g=M$, or in the group of women, $g=W$, and $X_{g}$ is a vector of the individual characteristics of the person in group $g$ (e.g., age, education level). We use the Oaxaca-Blinder decomposition (Blinder, 1973; Oaxaca, 1973) to decompose the gender earnings gap into the components that can be assigned to each set of control variables in the following manner. Separate OLS regressions are estimated for men and women: $y_{g}=X_{g} \beta_{g}+v_{g}$, where $\beta_{g}$ are the returns to the people's characteristics. 
The gender gap can be expressed as:

$$
\hat{\Delta}^{\mu}=\bar{Y}_{M}-\bar{Y}_{W}=\bar{X}_{M} \hat{\beta}_{M}-\bar{X}_{W} \hat{\beta}_{W}=\bar{X}_{M}\left(\hat{\beta}_{M}-\hat{\beta}_{W}\right)+\left(\bar{X}_{M}-\bar{X}_{W}\right) \hat{\beta}_{W}
$$

This allows us to quantify the differences in earnings between men and women that can be attributed to differences in characteristics $\left(\bar{X}_{M}-\bar{X}_{W}\right)$ versus those that are due to differences in how men and women are paid for the same characteristics $\left(\hat{\beta}_{M}-\hat{\beta}_{W}\right)$. The latter is usually considered "unexplained" and indicates discrimination in the labor market. The disadvantage of this approach is that it focuses exclusively on average effects, which can lead to a misleading assessment if the impact of covariates varies across the wage distribution.

Let $F_{Y_{g}}(y)$ be a distribution function for the variable $Y$ in the group $g$. This can be expressed by the conditional distribution $F_{Y_{g} \mid X_{g}}(y \mid X=x)$ of $Y$ and the joint distribution $F_{X_{g}}(X=x)$ of all elements of $X: F_{Y_{g}}(y)=\int F_{Y_{g} \mid X_{g}}(y \mid X=x) \cdot F_{X_{g}}(X) d x, g=M, W$.

The mean decomposition analysis may be extended to the case of differences between the two distributions using a counterfactual distribution:

$$
F_{Y_{W}^{C}}(y)=\int F_{Y_{W} \mid X_{W}}(y \mid X) \cdot d F_{X_{M}}(X)
$$

This is the distribution of earnings that would prevail for people from group $W$ if they had the distribution of features from group $M$. Then we can write the following decomposition:

$$
F_{Y_{M}}(y)-F_{Y_{W}}(y)=\left[F_{Y_{M}}(y)-F_{Y_{W}^{C}}(y)\right]+\left[F_{Y_{W}^{C}}(y)-F_{Y_{W}}(y)\right]
$$

The first term on the right hand side of the equation (3) represents the unexplained effect and the second term gives the explained effect.

The counterfactual distribution can be constructed using the residual imputation method (JMP-approach) (Juhn et al., 1993). In this method, we estimate the two equations: $y_{W i}=X_{W i} \beta_{W}+v_{W i}$ and $y_{M i}=X_{M i} \beta_{M}+v_{M i}, i=1, \ldots, n$. Then the income $y_{M}$ from group $M$ is replaced with the counterfactual income $y_{W}^{C}$, where both the returns to the observables and residuals are set to be as in the group $W$. The procedure is carried out in two steps (see Fortin et al., 2010):

- unobservables are replaced by counterfactual unobservables assuming the rank preservation: $y_{W i}^{C, 1}=X_{M i} \beta_{M}+v_{W i}^{C, 1}, i=1, \ldots, n$, where $v_{W i}^{C, 1}=F_{v_{W} \mid X}^{-1}\left(\tau_{M i}\left(X_{M i}\right), X_{M i}\right)$ and $\tau_{M i}\left(X_{M i}\right)$ is the conditional rank of $v_{M i}$ in the distribution of residuals for $M$. Assuming that the regression residuals $v_{g}$ are independent of $X$, we compute the rank of the residual $v_{M i}$ in the marginal distribution of residuals for group $M$, and then choose the corresponding residual in the marginal distribution of residuals for group 
$W$. E.g., if $v_{M i}$ is at the $40^{\text {th }}$ percentile of the distribution of residuals for men, then $v_{W i}^{C, 1}$ will be the $40^{\text {th }}$ percentile of the distribution of residuals for women.

- counterfactual returns to observables are imputed as follows:

$$
y_{W i}^{C, 2}=X_{M i} \beta_{W}+v_{W i}^{C, 1}, i=1, \ldots, n .
$$

The rank preservation assumption means that "someone with the same unobserved skills would be in exactly the same position, conditional on $X^{\prime}$, in group $M$ or $W$ (Fortin et al., 2010, p. 58). This assumption is very strong and can be seen, along with the assumption of independence, as a limitation of the JMP-approach.

\section{Data used and results of the empirical study}

The empirical data used have been collected within the Structure of Earnings Survey (SES) for Poland in October 2014 (project RPP 333/2017-SES-EHIS-HBS “Labour market characteristics of the caregivers"). The SES is conducted every four years in the Member States of the European Union (although it is worth mentioning that in Poland the survey is conducted every two years) and provides comparable information at EU level on relationships between the level of earnings, individual characteristics of employees (sex, age, occupation, length of service, educational level) and their employer (economic activity, size of the enterprise, etc.).

The SES covers businesses with at least 10 employees and all economic activities defined in sections $\mathrm{B}$ to $\mathrm{N}$, and $\mathrm{P}$ to $\mathrm{S}$, of the Statistical classification of economic activities in the European Communities (NACE Rev 2). In our analysis, we focus on people performing the professions listed in the document Structure of the International Standard Classification of Occupations (ISCO-08). In particular, we analyze three data sub-samples:

- the first one, covering the entire sample (people of all professions),

- the second one, covering a group of teaching professionals (the ISCO-08 sub-major group No. 23; primary, secondary and vocational education teachers as well as university and higher education teachers),

- the third one with university and higher education teachers (the ISCO-08 minor group No. 231).

The whole sample consists of 723,706 observations, the second 69,022 , and the third group includes 10,423 observations.

Each person in the data sample is described by the following characteristics:

- gender (1 - men, 0 - women), age (age group category, from 1 to 5), 
- educlevel (highest successfully completed level of education and training, 1 - primary, 2 - secondary, 3 - post-secondary, 4 - higher and doctoral education (according to ISCED-97)),

- permanent (type of employment contract, 1 - permanent job/work contract of unlimited duration, 0 - temporary contract of limited duration),

- fulltime ( 1 - full-time, 0 - part-time employee),

- hours (number of hours paid during the reference month),

- holidays (annual days of holiday leave, in full days).

The sample features are presented in Table 1.

In the SES gross earnings cover remuneration in cash and in kind before any tax deductions and social security contributions payable by wage earners and retained by the employer. In our empirical decomposition analysis, the average gross hourly earnings in the month measured in Polish zlotys (hearn) of men were compared with those obtained by women. The logarithm of the average gross hourly earnings in the month (loghearn) constitutes the outcome variable.

Table 1. The selected sample features

\begin{tabular}{|c|c|c|c|c|c|c|c|c|}
\hline \multicolumn{2}{|c|}{ Characteristic } & Men & Women & \multicolumn{2}{|c|}{ Characteristic } & \multicolumn{2}{|c|}{ Men } & Women \\
\hline \multirow{4}{*}{ Educlevel } & $=1$ & $6.28 \%$ & $4.69 \%$ & \multirow{2}{*}{ Permanent } & $=0$ & \multicolumn{2}{|c|}{$26.13 \%$} & $24.47 \%$ \\
\hline & $=2$ & $60.70 \%$ & $45.00 \%$ & & $=1$ & \multicolumn{2}{|c|}{$73.87 \%$} & $75.53 \%$ \\
\hline & $=3$ & $8.06 \%$ & $8.79 \%$ & \multirow{2}{*}{ Fulltime } & $=0$ & \multicolumn{2}{|c|}{$5.61 \%$} & $9.74 \%$ \\
\hline & $=4$ & $24.96 \%$ & $41.51 \%$ & & $=1$ & \multicolumn{2}{|c|}{$94.39 \%$} & $90.26 \%$ \\
\hline Average hours & & 180.04 & 167.01 & Average holidays & & \multicolumn{2}{|c|}{22.90} & 24.95 \\
\hline \multicolumn{4}{|c|}{ Characteristic } & $\begin{array}{c}\text { All } \\
\text { professions }\end{array}$ & \multicolumn{2}{|c|}{$\begin{array}{c}\text { Teaching } \\
\text { professionals }\end{array}$} & $\begin{array}{r}\text { U1 } \\
\text { Hig }\end{array}$ & $\begin{array}{l}\text { versity and } \\
\text { er Education } \\
\text { eachers }\end{array}$ \\
\hline \multicolumn{9}{|c|}{ Whole sample } \\
\hline \multicolumn{4}{|l|}{ No. of obs. } & 723,706 & \multicolumn{2}{|c|}{69,022} & \multicolumn{2}{|r|}{10,423} \\
\hline \multicolumn{4}{|c|}{ gross annual earnings in year in PLN } & 48,225 & \multicolumn{2}{|c|}{48,279} & & 70,619 \\
\hline \multicolumn{4}{|c|}{ avg gross earnings in month in PLN } & 4,208 & \multicolumn{2}{|c|}{4,225} & & 6,014 \\
\hline \multicolumn{4}{|c|}{ avg gross hourly earnings in month in PLN (hearn) } & 24.94 & \multicolumn{2}{|c|}{41.20} & & 36.45 \\
\hline \multicolumn{9}{|c|}{ Men } \\
\hline \multicolumn{4}{|l|}{ No. of obs. } & 359,794 & \multicolumn{2}{|c|}{17,051} & & 5,850 \\
\hline \multicolumn{4}{|c|}{ gross annual earnings in year in PLN } & 53,542 & \multicolumn{2}{|c|}{52,157} & & 75,564 \\
\hline \multicolumn{4}{|c|}{ avg gross earnings in month in PLN } & 4,687 & \multicolumn{2}{|c|}{4,529} & & 6,433 \\
\hline \multicolumn{4}{|c|}{ avg gross hourly earnings in month in PLN (hearn) } & 26.33 & \multicolumn{2}{|c|}{41.07} & & 38.90 \\
\hline \multicolumn{9}{|c|}{ Women } \\
\hline \multicolumn{4}{|l|}{ No. of obs. } & 363,912 & 51, & & & 4,573 \\
\hline gross annual ea & $\mathrm{s}$ in ye & $n$ PLN & & 42,967 & 47, & & & 64,295 \\
\hline avg gross earni & mont & PLN & & 3,734 & & & & 5,478 \\
\hline avg gross hourl & ings $i$ & onth in PLI & earn) & 23.58 & 41.2 & & & 33.31 \\
\hline
\end{tabular}

Source: own calculations. 


\section{Empirical Analysis}

\subsection{Results of Oaxaca-Blinder decomposition for differences in log hourly earnings}

In what follows the Oaxaca-Blinder two-component decomposition is used to answer the question of how much of the earnings gap between men and women can be attributed to the differences in the characteristics of individuals and how much remains unexplained.

Table 2 presents the estimated values of the aggregate Oaxaca-Blinder decomposition of inequalities between men's and women's log hourly earnings for the whole sample, for the subsample restricted to the teaching professionals and for the subsample of the university and higher education teachers.

Table 2. The Oaxaca-Blinder decomposition of the average log hourly earnings differences

\begin{tabular}{|l|c|c|c|}
\cline { 2 - 4 } \multicolumn{1}{c|}{} & All professions & Teaching professionals & $\begin{array}{c}\text { University } \\
\text { and Higher Education Teachers }\end{array}$ \\
\hline Mean loghearn men & 3.079 & 3.648 & 3.550 \\
\hline Mean loghearn women & 2.995 & 3.663 & 3.421 \\
\hline Raw differential & 0.085 & -0.015 & 0.129 \\
\hline Unexplained effect & 0.232 & 0.038 & 0.076 \\
\hline Explained effect & -0.148 & -0.053 & 0.053 \\
\hline Percent unexplained & 276 & -253 & 59 \\
\hline Percent explained & -176 & 353 & 41 \\
\hline
\end{tabular}

Source: own elaboration using the Stata command 'decompose'.

The predicted hourly earnings are the highest for teaching professionals, then for university and higher education teachers, and finally when we calculate them for employees of the entire economy. There is a positive difference between the mean values of log hourly earnings for men and women in the entire economy (0.085). It means that the average hourly earnings of men in the whole sample are $8.5 \%$ higher than in the case of women. In the higher education sector, the calculated difference is much bigger $(0.129)$ but still positive. The raw differential is negative for teaching professionals $(-0.015)$, which means that among teachers, women's hourly earnings are on average higher than men's.

The difference between the mean log hourly earnings was decomposed into two components: the first one explaining the contribution of the different values of model's coefficients (the unexplained part) and the second one explaining the contribution of the attributes differences (the explained part). Considering all professions, it can be said that the unexplained effect is huge and positive $(0.232)$ and the explained is lower and negative $(-0.148)$. It means that the inequalities examined should be assigned in the majority to the coefficients of estimated models 
rather than to the differentiation of individual characteristics. The unexplained part of the gender pay gap gives us information about the wage discrimination of women in Poland. The negative value of the explained component means that the difference of the average log hourly earnings between men and women is reduced by the women's better characteristics.

When we restrict the sample only to teaching professionals, the opposite situation occurs. Within this subsample, the characteristics possessed by women increase the observed pay gap ("better" characteristics of women cause that they earn better than men). However, the unexplained part of the gap, which is positive, does not indicate the discrimination against men but still against women.

On the other hand, at universities and in higher education, differences in hourly earnings are to the disadvantage of women. A relatively high share of the gap is explained $(41 \%)$ and the observed characteristics of women (worse than for men) even enlarge the pay inequality (because the explained effect is positive). This result is very similar to the one obtained in the paper (Majchrowska et al., 2014), where for the group of academic teachers a significant part of the wage differences by gender is due to "worse" personal and job characteristics of women.

The detailed decomposition made it possible to isolate the factors explaining the inequality observed to a different extent. We do not present these results due to the lack of space. The reduction of the gap in the whole sample was mainly influenced by variables educlevel, permanent and hours, while the values of the variable fulltime caused the increase in the gap. In the education sector, the wage advantage of women was associated with the features: educlevel, permanent, fulltime and hours.

\subsection{Results of decomposition using the residual imputation approach}

Since the Oaxaca-Blinder technique focuses only on average effects, next, we present the decomposition of inequalities along the distribution of log hourly earnings for men and women using the JMP-approach. The results are shown in Table 3, where the inequalities are expressed in terms of percentiles. The symbols p5, .., p95 stand for 5th, .., 95th percentile (e.g. the 5 th percentile is the log hourly earnings value below which $5 \%$ of the observations may be found). For each of the seven percentiles the total differences between the values of log hourly earnings for men and women were computed. Then, these differences are expressed in terms of the unexplained and explained components. 
Table 3. The results of decomposition using the JMP-approach

\begin{tabular}{|c|c|c|c|c|c|c|}
\hline \multirow[t]{2}{*}{ Percentile } & \multicolumn{2}{|c|}{ All professions } & \multicolumn{2}{|c|}{$\begin{array}{c}\text { Teaching } \\
\text { professionals }\end{array}$} & \multicolumn{2}{|c|}{$\begin{array}{l}\text { University and Higher } \\
\text { Education Teachers }\end{array}$} \\
\hline & \multicolumn{6}{|c|}{ total difference } \\
\hline $\mathrm{p} 5$ & \multicolumn{2}{|c|}{-0.004} & \multicolumn{2}{|c|}{-0.051} & \multicolumn{2}{|c|}{0.020} \\
\hline p10 & \multicolumn{2}{|c|}{0.015} & \multicolumn{2}{|c|}{-0.012} & \multicolumn{2}{|c|}{0.054} \\
\hline p25 & \multicolumn{2}{|c|}{0.115} & \multicolumn{2}{|c|}{-0.023} & \multicolumn{2}{|c|}{0.116} \\
\hline p50 & \multicolumn{2}{|c|}{0.105} & \multicolumn{2}{|c|}{-0.041} & \multicolumn{2}{|c|}{0.122} \\
\hline p75 & \multicolumn{2}{|c|}{0.068} & \multicolumn{2}{|c|}{-0.025} & \multicolumn{2}{|c|}{0.147} \\
\hline p90 & \multicolumn{2}{|c|}{0.015} & \multicolumn{2}{|c|}{0.016} & \multicolumn{2}{|c|}{0.202} \\
\hline p95 & \multicolumn{2}{|c|}{0.122} & \multicolumn{2}{|c|}{0.082} & \multicolumn{2}{|c|}{0.246} \\
\hline \multirow{2}{*}{ Percentile } & \multicolumn{6}{|c|}{ Unexplained and explained components } \\
\hline & unexpl. & expl. & unexpl. & expl. & unexpl. & expl. \\
\hline $\mathrm{p} 5$ & 0.079 & -0.083 & 0.058 & -0.109 & 0.002 & 0.018 \\
\hline p10 & 0.120 & -0.104 & 0.087 & -0.099 & 0.017 & 0.037 \\
\hline p25 & 0.194 & -0.078 & 0.080 & -0.103 & 0.057 & 0.059 \\
\hline p50 & 0.249 & -0.144 & 0.055 & -0.096 & 0.083 & 0.040 \\
\hline p75 & 0.301 & -0.233 & 0.043 & -0.068 & 0.101 & 0.046 \\
\hline p90 & 0.277 & -0.262 & 0.055 & -0.039 & 0.120 & 0.082 \\
\hline p95 & 0.233 & -0.111 & 0.124 & -0.042 & 0.148 & 0.098 \\
\hline
\end{tabular}

Source: own elaboration using the Stata command 'jmpierce'.

For people of all professions and for the university and higher education teachers the differences between the values of log hourly earnings for men and women along the whole earnings distribution are mostly positive. The positive values obtained indicate higher hourly earnings for men than for women. Going across the rows to compare quantile effects shows that the total differences are smaller at the bottom and greater at the top of the distribution.

Only for teaching professionals the differences between the values of log hourly earnings for men and women along the whole earnings distribution are first negative and then become positive among the highest paid teachers (here the hourly wage for men is higher than for women).

Figure 1 contains the total, explained and unexplained differences between the log earnings distributions for men and women vs. quantile rank in all three sub-samples analyzed. It can be said that the total effect most often grows along the distribution. 


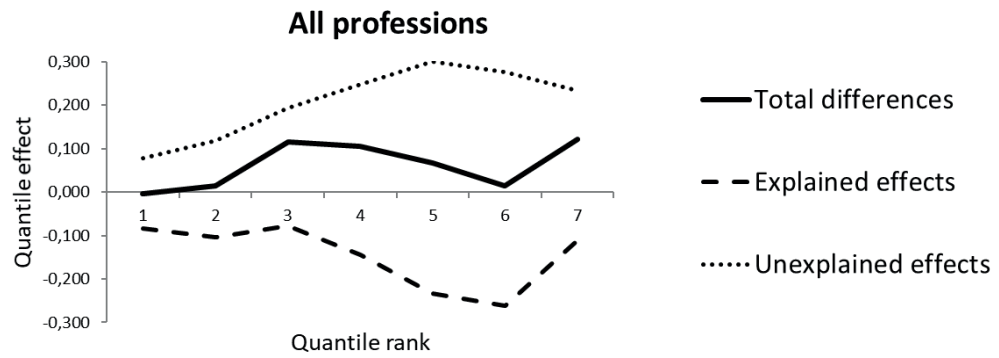

Teaching professionals

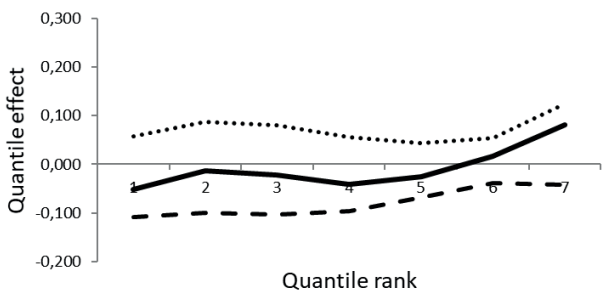

University and Higher Education Teachers

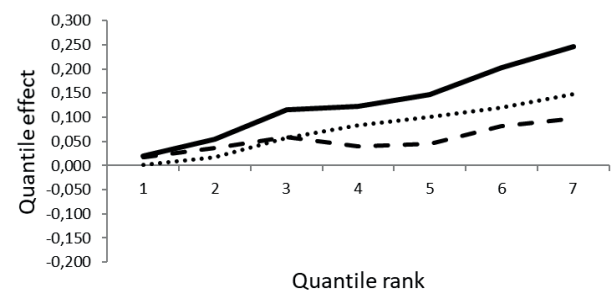

Figure 1. The total, the unexplained and the explained differences between the log hourly earnings distributions for men and women calculated using the JMP-approach

Source: own elaboration using 'jmpierce' Stata module.

We note that the greatest inequalities are among the highest-paid academic staff. Also, only for academic teachers the explained effects are positive. The positive values mean that the different values of men's and women's attributes increase the earnings inequalities in all of the earnings ranges (it may be that the differences are increased by the men's better or women's worse professional qualities, especially in the upper ranges of earnings). The positive unexplained effects (effects of coefficients) are bigger than the explained, and they are the result of differences in the "market prices" of individual characteristics of men and women (interpreted as the women labor market discrimination). The size of discrimination is the highest for the best-paid academic positions.

\section{Conclusions}

The aim of the study was to compare hourly earnings for men and women in Poland, with particular emphasis on the education sector. We started with the decomposition of the average values for log hourly earnings using the Oaxaca-Blinder method. The findings are to a great extent similar to those shown by Majchrowska et al. (2014). The analysis of the statistical data 
shown that on average hourly earnings of men in the whole sample were $8.5 \%$ higher than in the case of women. When we restricted our sample to the education sector the unadjusted gender wage gap changed in favor of women to $-1.5 \%$. Among academic teachers only, we noted a huge positive gap (12.9\%). The unexplained part of the earnings gap gave us information about the size of wage discrimination. Women were discriminated against in terms of pay in the entire economy, among the teaching professionals and in the academic sector (due to the estimated positive values of unexplained components).

Further, we extended the decomposition procedure to different quantile points along the whole earnings distribution. In this case, to decompose the inequalities between log hourly earnings along the whole distribution we used the JMP-residual imputation approach. In the group of teachers, the hourly earnings of women were on average higher than the earnings of men (due to "better" characteristics of women in this profession) but not for the highest earnings values. When the gap was observed in favor of men, it was generally higher at the top of the wage distribution. Especially, the results for academic teachers indicate that the total effect increases along the distribution.

The obtained results indicate that male faculty members earn more compared to their female colleagues, which is consistent with the results of a lot of foreign research (e.g., Barbezat and Hughes (2005), Chen and Crown (2019)). Researchers, using empirical data, have also identified other forms of gender discrimination in the academic community. For example, there is evidence of barriers in the peer review process (Hengel, 2017) or in the hiring process (e.g., Antecol, Bedard and Stearns (2018) showed how post-birth leave rules reduce the likelihood that women will get a full-time job compared to their male counterparts).

In general, our results confirm the findings of previous studies. We show that looking at the average effects may give imprecise results as among occupational groups there are the ones where women earn more than men and the ones where men earn better. It can be also said that only a fraction of the gender wage gap can be explained by the different characteristics of men and women.

However, while interpreting the results presented above we have to remember that they are strictly linked with the data set used, the definition of the sample, the definition of the dependent variable, and the set of control variables in the empirical specification. The main limitation of the study, as stated in the Data section, is that it consists only of the individuals employed in firms having at least 10 workers, excluding agriculture, public administration and defense workers. The study covers 77,468 of 14,5634 thousand individuals working in Poland in 2014. As a result, the magnitude of the earnings gap and its decomposition cannot be 
directly compared with previous studies. Moreover, these findings should not be used to infer conclusions on the full labour market.

\section{References}

Addison, J.T., Ozturk, O.D., Wang, S. (2018). The Occupational Feminization of Wages. Industrial and Labor Relations Review, 71 (1), 208-241. DOI: 10.1177/0019793917708314.

Antecol, H., Bedard, K., Stearns, J. (2018). Equal but Inequitable: Who Benefits from GenderNeutral Tenure Clock Stopping Policies? American Economic Review, 108 (9), 24202441. DOI: 10.1257/aer.20160613.

Barbezat, D.A., Hughes, J.W. (2005). Salary Structure Effects and the Gender Pay Gap in Academia. Research in Higher Education, 46 (6), 621-640. DOI: 10.1007/s11162-004-4137-1.

Bergman, B.R. (1971). The Effecton on White Incomes if Discrimination in Employment. Journal of Political Economy, 79 (2), 294-313. DOI: 10.1086/259744.

Blinder, A. (1973). Wage Discrimination: Reduced Form and Structural Estimates. Journal of Human Resources, 8 (4), 436-455. DOI: 10.2307/144855.

Chen, J.J., Crown, D. (2019). The Gender Pay Gap in Academia: Evidence from the Ohio State University. American Journal of Agricultural Economics, 101 (5), 1337-1352. DOI: 10.1093/ajae/aaz017.

Cukrowska-Torzewska, E., Lovasz, A. (2016). Are children driving the gender wage gap? Comparative evidence from Poland and Hungary. Economics of Transition, 24 (2), 259-297. DOI: $10.1111 /$ ecot.12090.

DiNardo, J., Fortin, N.M., Lemieux, T. (1996). Labor Market Institutions and the Distribution of Wages, 1973-1992: A Semiparametric Approach. Econometrica, 64 (5), 1001-1044. DOI: $10.2307 / 2171954$.

Donald, S.G., Green, D.A., Paarsch, H.J. (2000). Differences in Wage Distributions between Canada and the United States: An Application of a Flexible Estimator of Distribution Functions in the Presence of Covariates. Review of Economic Studies, 67 (4), 609-633. DOI: $10.1111 / 1467-937 X .00147$.

Fortin, N., Lemieux, T., Firpo, S. (2010). Decomposition Methods in Economics. National Bureau of Economic Research Working Paper Series, 16045. DOI: 10.3386/w16045.

Goraus, K., Tyrowicz, J., van der Velde, L. (2017). Which Gender Wage Gap Estimates to Trust? A Comparative Analysis. Review of Income and Wealth, 63 (1), 118-146. DOI: 10.1111/ roiw. 12209 . 
Hengel, E. (2017). Publishing while Female. Are Women Held to Higher Standards? Evidence from Peer Review. Cambridge Working Papers in Economics, 1753, University of Cambridge.

Juhn, Ch., Murphy, K.M., Pierce, B. (1993). Wage inequality and the rise in returns to skill. Journal of Political Economy, 101, 410-442. DOI: 10.1086/261881.

Landmesser, J. (2016). Decomposition of Differences in Income Distributions Using Quantile Regression. Statistics in Transition - new series, 17 (2), 331-348. DOI: 10.21307/stattrans-2016-023.

Landmesser, J.M., Karpio, K., Łukasiewicz, P. (2015). Decomposition of Differences Between Personal Incomes Distributions in Poland. Quantitative Methods in Economics, XVI (2), 43-52.

Machado, J.F., Mata, J. (2005). Counterfactual decomposition of changes in wage distributions using quantile regression. Journal of Applied Econometrics, 20, 445-465. DOI: 10.1002/ jae. 788 .

Majchrowska, A., Strawiński, P., Konopczak, K., Skierska, A. (2014). Why are women paid less than men? An investigation into gender wage gap in Poland. Working Papers, 31/2014 (148), Faculty of Economic Sciences, University of Warsaw.

Matysiak, A., Baranowska, A., Słoczyński, T. (2010). Kobiety i mężczyźni na rynku pracy. In: M. Bukowski (ed.). Zatrudnienie w Polsce 2008 - Praca w cyklu życia. Warszawa: Human Resources Development Center.

Oaxaca, R. (1973). Male-female wage differentials in urban labor markets. International Economic Review, 14 (3), 693-709. DOI: 10.2307/2525981.

Słoczyński, T. (2012). Próba wyjaśnienia regionalnego zróżnicowania międzypłciowej luki płacowej w Polsce. Studia Regionalne i Lokalne, 3 (49), 65-84.

Śliwicki, D., Ryczkowski, M. (2014). Gender Pay Gap in the micro level - case of Poland. Quantitative Methods in Economics, XV (1), 159-173.

Zajkowska, O. (2013). Gender Pay Gap in Poland - Blinder-Oaxaca Decomposition. Quantitative Methods in Economics, XIV (2), 272-278. 